\title{
HIST1H3C NM_003531.2:C.83A>T
}

National Cancer Institute

\section{Source}

National Cancer Institute. HIST1H3C NM 003531.2:C.83A>T. NCI Thesaurus. Code

C154313.

A nucleotide substitution at position 83 of the coding sequence of the HIST $1 \mathrm{H} 3 \mathrm{C}$ gene where adenine has been mutated to thymine. 